\title{
HACIA UNA ANTROPOLOGIA DE LA INDUMENTARIA: EL CASO DE LOS GUAMBIANOS
}

\author{
Ronald A. Schwarz, Ph. D. \\ Tulane University - Universidad del Valle \\ International Center for Medical Research
}


Los trajes son temas sobre el cual debían expresarse con frecuencia los antropólogos, pero ha ocurrido precisamente lo contrario: se ha mantenido un silencio sospechoso. El idioma y la fabricación de utensilios han sido considerados siempre entre las características distintivas del hombre, pero lo que concierne al vestir ha recibido escasa atención. En los textos recientes de Antropología Social (Beattie, 1964; Lienhardt 1964; Mair, 1965) las alusiones al tema son tan escasas que cualquier lector desprevenido podría concluír razonablemente que los nativos viven desnudos. El silencio de los antropólogos se parece en algo, aunque tal vez por razones diferentes, al de los Hombres Importantes de Nueva York para quienes el vestuario es un asunto de capital importancia, aunque sobre el particular no se mencione palabra alguna.

... el vicio secreto de ... vestir a la medida... Prácticamente todos los hombres más influyentes de Nueva York... son fanáticos sobre las ventajas marginales del vestir a la medida.

Estas constituyen como una especie de insignia secreta para ellos y sin embargo, el tema es un tabú. Ni siquiera quieren dar la impresión de que se interesan al respecto. (Tom Wolfe, 1966, pp. 231-2).

¿Y por qué ha de ocuparse la Antropología con el tema de la indumentaria? Simplemente porque en todas partes del mundo que se encuentre el hombre, éste mono desnudo que él es, hace algo para vestirse o adornarse y lo está haciendo desde hace mucho tiempo.

Si bien habremos de tocar las razones por las cuales los antropólogos se niegan a concederle a los elementos de la indumentaria la misma atención que a otros aspectos de la cultura, el fin primordial de este estudio es el de sacar a la luz lo que se ha escrito al respecto y a la vez, 
desarrollar las bases teóricas y los principios metodológicos apropiados para darle al tema de la indumentaria un puesto dentro de la antropología.

Sobre el particular en las ciencias sociales todavía falta por aclarar algunas definiciones, porque con frecuencia se emplean los términos vestuario, ornamentos, vestidos, adornos y trajes en forma general. Además, existen prácticas tales como deformación de la cabeza, impresión de tatuajes, pintura del cuerpo y peinado del cabello, que son todas formas de modificar el cuerpo. Puesto que no considero el caso de entrar a evaluar los méritos y deméritos de esta terminología, habré de emplear la palabra indumentaria indistintamente para referirme a todas las formas de modificación corporal; desde un tapón para el oído hasta un traje hecho a mano.

\section{ORIGENES Y FUNCIONES DE LA INDUMENTARIA}

El hombre nace desnudo, pero muere y es enterrado vestido (Hiler, 1939; xiii)

En su libro sobre los orígenes del arte (The Origins of Art: A Psychological and Sociological Inquiry), publicado en 1900 , el auto Hirn examina los orígenes de la auto-decoración (pp. 214-227). Tras evaluar concienzudamente las evidencias etnológicas existentes y de tomar en cuenta las teorías sobre el origen de los adornos, concluye afirmar en cuenta las teorias sobre ecidir a ciencia cierta el porqué el hombre empezó a decorarse. Es de lamentar que la antropología se haya desentendido desde hace algún tiempo de averiguar los orígenes del vestido y que por lo tanto, en estos últimos setenta y tres (73) años no se haya dicho nada que haga modificar las conclusiones de Hirn. Debemos recono resulta imposible de probar que un conjunto determinado de sentimientos dio origen a la costumbre de adornarse, sería aun más lamentable que la lógica de las ciencias sociales interfiriera con nuestra curiosidad sobre un tema tan fundamental.

\section{Los Adornos: Indicios de los primates y arqueólogos}

Existen indicios positivos de que la tendencia a decorarse el cuerpo está arraigada en nuestra herencia de primates. Los chimpancés o por lo menos aquellos en la cautividad, se muestran divertidos decorándose con trapos y cuerdas, pintándose el cuerpo y retozando con ánimo exhibicionista, aunque no se hayan podido establecer nexos de regularidad o continuidad de estilo en los adornos de los primates. En consecuencia, el vestirse o adornarse, aún si hemos de concederle la inspiración de nuestros antepasados pre-humanos, resulta ser un producto esencialmente humano, como lo han sido el lenguaje y la fabricación de herramientas.

En arqueología, la evidencia más remota de adornos se encuentra en los huesos de tumbas Neanderthal del Paleolítico Medio, donde al parecer se utilizaban arcillas ocrosas. Los textiles no han sobrevivido en estos depósitos remotos y los huesos de dientes y las conchas, junto con los dibujos en las cavernas, solo aparecen en el período Auriñaciense. Las primeras agujas con ojo y hechas de hueso aparecen durante este período y nos revelan indicios de costura. De sitios Auriñacienses también provienen las figurillas femeninas con características sexuales prominentes y adornadas con brazaletes; pero las prendas de vestir y los primeros indicios de tejidos no aparecen sino hasta el período Neolítico (Beals y Hoijer, 1959 pp. 383-84; Benedict, 1931, pp. 235).

Buena parte de las teorías sobre el origen de los adornos se deriva de los estudios realizados entre las sociedades primitivas y tribales (Benedict, 1931; Bliss, 1916; Bunzel, 1931; Crawley, 1931; Dunlap, 1928; Fluzel, 1929, 1930, 1945; Harm, 1938; Hiler, H., 1929; Hiler, H. y M., 1939; Hirn, 1900; Sanborn, 1929; Thomas, 1909). Algunos de estos autores entrar a aceptar cierta teoría, aunque la mayoría reconoce que en el origen y la evolución del vestuario han intervenido factores de orden ambiental, psicológico y sociocultural. Además, .los motivos para llegar a utilizar y adoptar cierta prenda de vestir pueden ser diferentes a los que inicialmente indujeron a su uso. Podemos dividir las diferentes teorías sobre el particular así:

\section{Protección del Ambiente}

Este punto de vista sostiene que la indumentaria, incluyendo tanto los ornamentos como las decoraciones, es la reacción humana a ciertas condiciones ambientales y a la necesidad de protegerse contra la incomodidad.

Si bien es cierto que existe una estrecha relación entre el vestuario y las condiciones ecológicas de ciertas regiones, también se encuentran 
áreas del mundo, tales como las zonas heladas de Tierra del Fuego y Australia, donde era de presumirse el uso de prendas protectoras y sin embargo, no ocurre así. Es de notar sí que aunque los Fueguinos y los aborígenes Australianos carecen de prendas exteriores de vestir, la costumbre de pintarse el cuerpo es común entre ambos pueblos.

\section{Protección contra las Fuerzas Sobrenaturales}

Hay autores como Hirn, 1900; Spencer y Guillen, 1899 y Frazer, 1915 que relacionan el origen y la función principal de los, vestidos primitivos con la necesidad que tiene el hombre de defenderse de espiritus malignos. Hirn, escribiendo en 1900 (pp. 217-219) resume así las primeras evidencias antropológicas a este respecto ( $p$ 217):

Es probable... que haya muchos pueblos primitivos que, de manera parecida a los aborígenes de las Nuevas Hébridas, se cubren el cuerpo muy escrupulosamente "no tanto por decencia, sino para evitar Nakar, es decir, influencias mágicas", pudiendo resultar peligroso aun la más leve mirada a la desnudez ajena.

Así mismo, dirigiéndose a aquellos escritores de la época dispuestos a aceptar "la moral" o la modestia, como razón para que el hombre tendiera a cubrirse las áreas genitales, escribe lo siguiente (Hirn, p. 218):

...es claro que aún antes de que se efectuaran tales transformaciones hacia la moralidad, la preocupación por la tranquilidad social debió haber inducido a los hombres a ocultar el sitio de tan peligrosa influencia.

Creencias acerca del poder de las fuerzas sobrenaturales para causar enfermedad, muerte y hasta embarazo son tan extendidas como el uso mismo de ornamentos. Este poder reside en los espíritus que animan a aquellos fenómenos naturales como el viento, la lluvia, el rayo, los ríos, el sol y la luna.

Aunque se precisa de un examen más amplio de la literatura etnográfica sobre el particular, se puede entrar a concluír que el uso de las prendas de indumentaria como protección de los malos espíritus es un motivo que aparece con frecuencia entre los pueblos primitivos y las sociedades tribales.

\section{La Hipótesis sobre el Pudor}

La teoría según la cual los hombres se cubren el cuerpo por un sentido del pudor se fundamenta en las historias bíblicas sobre la seducción de Eva por la serpiente y también se aducen al caso algunas leyendas encontradas entre los indios norteamericanos.

Según esta teoría el vestido llegó a adoptarse para ocultar los órganos genitales, debido a un sentido del pudor y de la modestia y a partir de la hoja de parra se evolucionó hacia indumentarias más complejas (Dunlap, 1928, p. 64; Sanborn, 1926, p. 2 ).

Esta teoría ha sido debatida insistentemente, por gran número de autores, como por ejemplo Hirn, 1900 y Westermarck, 1921 y su popularidad se deriva más del ambiente moralista que imperó en el siglo diecinueve, que de la evidencia etnológica. Dunlap, $(1928$, p. 66) nos senala la relación precisa entre la desnudez y la inmodestia cuando escribre lo siguiente:

Cualesquiera vestimenta, aún la más completa desnudez, puede llegar a ser modesta tan pronto como nos acostumbremos totalmente a ella. Así mismo, cualquier cambio de indumentaria efectuado repentinamente puede ser inmodesto si es de tal naturaleza que resulta conspicuo... El vestido en sí no tiene ni modestia ni inmodestia.

\section{La Hipótesis sobre la Atracción}

Esta tal vez es la primera teoría concreta expuesta por antropólogos sobre el origen de la indumentaria. Ellis en 1913 y Westermarck en 1921 sostuvieron que el propósito original de los vestidos fue el de atraer atención hacia los genitales y sus funciones eróticas, con el objeto de aumentar el interés sexual del observador hacia el poseedor de la prenda. Este punto de vista concuerda con las teorías al respecto de Simmel (1950) y Goffman (1959), quienes argumentaban que el ocultamiento y la reserva estimulaban el interés, mientras que la familiaridad resultaba en indiferencia.

Recientemente Bick (1968) ha planteado una versión modificada de la teoría de la atracción, según la cual todas las personas una vez pa- 
sada la edad de la pubertad se pueden considerar como consumidores y a la vez, objetos de consumo dentro del "mercado sexual" (p.3). En estas condiciones, la indumentaria

...puede entenderse como un sistema simbólico que daría señales sobre los deseos de un individuo de participar en un momento dado en ese mercado, como un objeto de consumo... La indumentaria vendría a ser, en los términos de McLuhan, el medio aparentemente inconsciente de transmitir el mensaje sexual de cada individuo (p. 3 ).

Los deseos de atraer atención hacia lo nuestro y/o de comunicar el grado de disponibilidad personal dentro del mercado sexual, son puntos de importancia para ayudarnos a entender el origen y el empleo de la indumentaria, pero estos, al igual que los anteriores, nos resultan insuficientes por sí solos para conformar una teoría general sobre el tema.

\section{La Hipótesis sobre Status y Posición Social}

Esta teoría postula que los orígenes y quizás la función principal de toda forma de indumentaria, se desprende de la necesidad de distinguir a los miembros de una sociedad por edades, sexos y clases o casta. Según esto el aspecto erótico pasaría a un segundo plano.

Esta tesis se apoya en ciertas modificaciones al cuerpo, como la escarificación y la circuncisión, que son efectuadas a cierta edad. Si bien estas prácticas han sido asociadas por lo general con la madurez sexual, y a su vez con las posibilidades eróticas, las ceremonias de que van acompañadas indican algo más que la disponibilidad sexual. En realidad, hay participantes en estas ceremonias que han alcanzado la pubertad algún tiempo antes de celebarse el evento.

También puede ser verdad el caso de que los primeros adornos consistieron en artículos provenientes de la cacería y utilizados como ostentación de los cazadores.

En las coronas de plumas de los jefes Xingú... podemos apreciar lo que más tarde sería un ostentoso arreglo del botín de la caza, mediante el cual un cazador proclama sus hazañas (Hirn, 1900, pp. 221-222).
Benedict $(1931$, p. 236) hace notar que si bien la diferenciación de los sexos es un aspecto central de la indumentaria en muchas sociedades, existen así mismo regiones en las cuales no es fácil distinguir los sexos por el vestido que llevan y también otras, donde el vestido señala el status y los trofeos sociales. Y escribe al respecto que,

en las praderas de Norteamérica el vestido de los hombres es un heraldo de sus proezas de guerra, y en la costa Noroccidental el sombrero de un hombre estará compuesto de unidades cumulativas que designan su rango (Ibid., p. 236).

La indumentaria también juega papel de importancia como indicador del status de una persona perteneciente a una comunidad étnica o a una tribu en particular. Así por ejemplo, a los Nuerse los identifica por la ausencia de sus incisivos inferiores y dentro de ellos, a los hombres, por seis (6) cortadas en la ceja (Evans-Pritchard, 1940, p. 123). A un Tuareg se lo conoce por su velo azul y en las tierras altas de Guatemala la población indígena se divide en grupos territoriales y étnicos, cada uno de los cuales utiliza una indumentaria peculiar.

En suma, la capacidad de los vestidos para indicar el status y el rango de un individuo, prescindiendo de las diferencias marginales que puedan existir, es ilimitada y por tal razón no hay motivo para detenernos aquí a examinar sus particularidades.

\section{¿QUE LES SUCEDIO A LOS VESTIDOS?}

Está claro que los orígenes y las funciones de la indumentaria fue un asunto de interés entre los antropólogos de principios de este siglo; durante años posteriores se realizaron algunos trabajos sistemáticos sobre el tema. Así por ejemplo, la mayoría de los etnógrafos, como Bunzel (1952), Parsons (1936), Lewis (1930), Reichel-Dolmatoff (1961) y Vogt (1969), incluyen en sus monografías secciones descriptivas sobre vestidos y generalmente bajo la rúbrica de la cultura material. Pero hay una tendencia entre los antropólogos sociales educados en la Gran Bretaña a desentenderse del tema en la mayoría de sus escritos.

En los trabajos etnográficos escritos en las últimas décadas de 1940,1950 y 1960 se notan las dos corrientes de la antropología mo- 
derna. La primera tiende hacia un estudio de conjunto de las instituciones sociales y de sus mutuas relaciones funcionales, y la otra, hacia una especialización dentro de una sola institución, como por ejemplo el parentesco. Esta última corriente ha hecho esfuerzos por integrar la información y teorías antropológicas con los resultados de disciplinas afines como la economía, la política, la psicología clínica y el arte.

Por otra parte, los investigadores de la cultura material, quienes eran los encargados de estudiar lo referente a la indumentaria, se dedicaron con el tiempo más bien al estudio sistemático de la tecnología y de la ecología cultural, dejando de lado las vestimentas. Como resultado, el tema de la indumentaria fue suprimido por los especialistas en la tecnología y no ha llegado a ser del interés de quienes escriben sobre arte y estética; estos últimos se concentraron en campuss específicos de las artes: talla de madera, escultura, pintura, música y danzas.

Esta última afirmación queda ilustrada suficientemente por el contenido de tres volúmenes recientes sobre la antropología del arte y la estética, publicados por Helm, 1967; Otten, 1971; Joplin, 1971. En estos tratados se incluyen 65 artículos publicados entre 1949 y 1970 y sólo uno trata sobre la indumentaria (Sturtevant, 1971, pp. 160-174). La contribución de antropólogos está presente en un volumen que sobre la indumentaria y el orden social fue editado por Roach y Eicher en 1965, pero el libro es una colección ecléctica de extractos y artículos, que no entra a plantear un análisis crítico sobre el tema o a desarrollar una teoría general.

En resumidas cuentas se puede decir, que durante los últimos treinta (30) años se ha avanzado en los conocimientos sobre la tecnología, la psicología, la organización social y las artes del mono desnudo, pero nos resta por entender todavía su negativa a permanecer desnudo. En nuestro afán por la especialización y la integración de la antropología con otras ciencias hemos dejado colgada la indumentaria en el armario.

\section{SACANDO LAS ROPAS DEL ARMARIO}

La manera más fácil de indicar la importancia que tiene el vestido en una sociedad es reflexionando sobre lo que pasaría si no estuviera presente.
¡Qué haría su Majestad, fuera un accidente tal a ocurrir: que los botones simultáneamente se desprendieran y la sólida lana se evaporara como por arte de magia! ¡Cómo se vería a todos correr hacia los escondites más cercanos; sería una alta tragedia de Estado envuelta en una Farsa lamentable;... imaginarse toda la textura del Gobierno, la Legislación, la Propiedad, la Policía y la Sociedad Civilizada disuelta en gritos y gemidos... ¿Podrá un hombre concebir a un Duque de Windlestraw desnudo dirigirse a una Cámara de los Lores desnudo? La imaginación, como asfixiada por un aire Mefítico, se rebela contra sí misma y no concibe escena tal (Carlyle, 1954, p. 54).

El vestido no solamente indica el sexo, la edad, la ocupación y la posición social de una persona, sino que también va ligado a un conjunto de sentimientos, y sirve además para domar y canalizar emociones fuertes. Tal como ocurre con otros símbolos, el vestido tiene su aspecto conativo, es decir, que mueve a los hombres a actuar en formas prescritas. Y esta característica puede continuar aun después de que su contenido cognitivo ha dejado de aceptarse, como en el caso del católico convertido en ateísta que podrá seguir arrodillándose y persignándose dentro de una iglesia.

También, el vestido ayuda a definir situaciones dadas al realizar ciertas características y mantener ciertas otras en estado latente o de ambigüedad. Por ejemplo: entre los Fon de Dahomey el jefe de una aldea lleva puesto un sombrero cuando actúa en su capacidad de jefe, otro cuando cumple con sus deberes como titular de una línea de parentesco y aun otro, cuando actúa como jefe del hogar. En nuestra sociedad misma se recuerda el caso del policía en servicio y en ropas de civil.

Uno de los ejemplos más dicientes de cómo el vestido es un aspecto capital de la comunicación entre miembros de un grupo social se encuentra en la obra de Murphy (1964), en la cual el autor examina la relación entre las distancias sociales y el velo de los Tuareg. Para el efecto cita a Lhote (1955, pp. 308-9) sobre el empleo y la psicología del velo.

El estilo de llevar velo, de colocar sus partes sobre la cabeza, puede variar de una tribu a la otra y algunos individuos se lo colocan de acuerdo al gusto personal y a la moda local... Además de la moda existe el giro, mediante el cual se expresa la elegancia. Así 
también, existe una psicología del velo: por su manera de llevarlo se puede obtener una idea sobre el ánimo del envelado, así como entre nosotros es común establecer deducciones parecidas a juzgar por el sesgo del sombrero.

Entre los Tuareg, hay un estilo reservado y modesto como cuando se entra a un campamento donde hay mujeres presentes, un estilo elegante y rebuscado para ir a fiestas de gala, una forma altiva entre los guerreros conscientes de su importancia o una manera caprichosa la del vasallo o esclavo jactancioso. También se ven el estilo suelto y holgado del muchacho jovial o el desordenado del hombre inestable y temperamental. El velo también puede expresar sentimientos pasajeros como cuando se lo sube hasta los ojos frente a mujeres o personas importantes, o se lo mantiene bajo entre familiares y amigos. Para reírse animadamente de un chiste el Tuareg se levantará la parte baja de su velo bien en alto sobre la nariz y en caso de furia, se lo apretará como una correa para ocultar su enojo.

Este aspecto del vestido, de expresar y ocultar ciertos principios y emociones así como de impulsar a la gente a actuar en formas apropiadas, puede denominarse su aspecto simbólico o retórico. Por esa capacidad de simbolizar un orden social, es decir, lo que es y lo que debe ser, los vestidos juegan un papel dinámico en la acción y la comunicación social.

\section{HACIA UNA ANTROPOLOGIA DE LA INDUMENTARIA}

En esta sección haré un bosquejo de ideas e inquietudes sobre bases concretas, para dar a la indumentaria su enfoque antropológico y con esto se pretende más bien exponer principios que entrar a formular conclusiones. Para tal efecto hay dos áreas del estudio que es preciso distinguir analíticamente y que están estrechamente ligadas existencialmente: indumentaria con respecto a un pueblo e indumentaria con respecto al hombre. Por una parte existe la indumentaria de un pueblo en particular y de la sociedad en general; por otra, existe una íntima asociación entre la Naturaleza y el Hombre, su vestido y su cultura.
Como punto de partida para estos planteamientos se hace necesario despojar al hombre de sus atuendos para colocarlo firmemente en un plano naturalista y no, meramente, en el plano ecológico. Se puede correlacionar al hombre no solamente con aquello situado fuera de sí mismo sino también consigo mismo en un sentido biológico y filosófico. Toda su producción, bien sea una lanza, una casa, leyes, poemas o un par de zapatos, refleja las decisiones dentro de su medio ambiente con el cual está indisolublemente ligado, si bien una parte es de su propia creación.

Podemos así distinguir tres ( 3 ) formas de producción humana utilizando las categorías del filósofo Buchler (1955): lo que se hace, lo que se fabrica y lo que se dice. Debemos considerar estas como formas alternativas que posee un individuo de establecer relaciones con su mundo, pero hay que hacer hincapié en que son formas alternativas de producción, y que no cabe por consiguiente establecer una jerarquía filosófica o antropológica entre ellas.

La forma de producción dentro de la cual encajan los objetos de la cultura material como la indumentaria es "lo que se fabrica". A este respecto Buchler (1955, p. 12) dice lo siguiente:

Cuando un hombre talla la piedra, escoge sus ropas, compone música, o arregla los cubiertos en la mesa, en suma, cuando fabrica algo, está ordenando materiales de acuerdo con disposiciones establecidas o en evolución. Entra a juzgar sobre un conjunto natural de cosas al diseñar él mismo su estructura, o al modificar una estructura presente dentro del conjunto, es decir, adopta un cierto orden y descarta otro.

$\mathrm{La}$ forma en que un hombre ordena sus materiales, tanto como lo que dice al respecto, refleja su orientación personal y define así mismo el carácter de algo dentro de su mundo. La propiedad de las cosas se define cuando se entra en relación con ellas y esto tiene lugar no solo al decir algo sobre ellas, sino también al hacer con ellas o fabricar algo de ellas (pp. 12-13). "No es la mente la que juzga, sino el hombre mismo" (p 29).

De acuerdo con Buchler, las formas de juzgar son también formas de comunicarse. Nos comunicamos actuando y produciendo, así como también declarando algo; además el valor comunicativo de lo que producimos no se limita a lo que otros entiendan at respecto. 
El poder comunicativo de nuestra producción puede extenderse mucho más allá del propósito comunicativo de sus productores. Al convertirse en posesión comunal la producción afecta el comportamiento y la comprensión... El poder comunicativo de un producto no depende en manera alguna de su forma de producción, ni de la validez de su manifestación (Ibid, p. 30 ).

La aseveración de Buchler de que todas las tres ( 3 ) formas de juzgar son efectivas para la comunicación concuerda con la posición tomada por Berkeley dentro de la filosofía moderna, ampliada por Pierce y Royce, según la cual cualquier cosa puede servir como un signo: "cualquier cosa está sometida a interpretación y por lo tanto, resulta un medio posible de la comunicación" (p. 30).

Si nos hemos detenido un poco con estos planteamientos filosóficos es por dos razones de interés: La primera es con el objeto de situar la cultura material dentro de, lo que considero, una relación más apropiada con el comportamiento verbal y la acción social. La segunda es la de anticiparme a quienes puedan objetar que los antropólogos se deben limitar, en sus interpretaciones de signos y símbolos, a lo que digan sus informantes (ver Nadel, 1954; Wilson, 1957).

Al llegar a aceptar que lo que los hombres fabriquen o hagan puede ser tan importante como lo que digan para efectos de definir su relación con el medio ambiente (a la vez socio-cultural y natural), el estudio de la indumentaria se convierte en una tarea antropológica de dimensiones significativas. No basta el hecho de que solo los humanos se cubren el cuerpo, sino que más que ningún otro producto material, la indumentaria desarrolla papel simbólico en mediar las relaciones entre la naturaleza, el hombre y su ambiente socio-cultural. Al vestirse, el hombre se dirige a sí mismo, a sus semejantes y a su mundo.

\section{El contexto Natural y la Indumentaria}

La idea de que para entender simbolismos ha de observarse primero al cuerpo y al medio ambiente no es nueva en antropología. Así por ejemplo, Hertz (1960) nos suministra amplias observaciones para demostrar que el dualismo entre las manos derecha e izquierda es fuente de distinciones culturales en muchas sociedades. Otros como Douglas (1966), Levi-Strauss (1963) Needham (1958, 1960), Faron (1964) y Tuner $(1967,1969)$ han utilizado el concepto "derecha-izquierda" para estudiar relaciones entre los valores y las divisiones sociales, así como aspectos del comportamiento. Douglas (1970: vii) lleva las cosas aun más allá de "derecha-izquierda" para aseverar que "la mayor parte del comportamiento simbólico debe operar por necesidad a través del cuerpo humano" (subrayado mío). Sugiere ella además, que una vez establecidas las categorías sociales, estas entran a modificar la experiencia del cuerpo y suministran una estructura cultural para interpretar las relaciones sociales (p. 65). Sería válido tal vez añadir que el vestido desarrolla papel importantísimo exhibiendo juicios sobre la clasificación corporal y tal como se ha dicho con anterioridad, estos juicios son puntos de apoyo para la estructura cultural y las relaciones sociales.

Otra fuente obvia de estabilidad y regularidad estructural de procesos, como lo es el cuerpo, es el medio ambiente natural. Tanto los elementos ecológicos como los anatómicos, ofrecen alternativas y obstáculos a un individuo a su vez, se presentan como una base natural para construír unidades sociales y sus diferentes relaciones. Hughes (1965, p. 11) se encarga de ilustrarnos este punto cuando escribe:

El concepto del "medio ambiente" no debe convertirse en categoría residual, muda, sobre la cual se sostienen las complejidades del organismo individual, o se ilumina la figura de la personalidad humana, puesto que el ambiente en sí está definido de antemano: posee puntos salientes, de estructura, de orientación forzosa para el organismo que percibe... él (el ambiente) es... un fondo de alternativas y obstáculos estructurados en términos tanto físicos como sociales.

Se hace necesario entonces asignarle importancia a la naturaleza, puesto que ella aporta la materia prima de los vestidos y adornos, así como también una base potencial para establecer los criterios del hombre sobre su cuerpo y su indumentaria. Por lo tanto, si hemos de desarrollar una antropología precisa de la indumentaria, no debemos contentarnos con examinar el contexto y el uso social de las prendas, sino que debemos incluír en nuestra apreciación el contexto natural conformado por el cuerpo humano y el ambiente natural. Sin embargo, las conclusiones que se puedan extraer sobre el particular deberán descansar en análisis sistemáticos de los hechos, y no sobre argumentaciones filosóficas o teorías antropológicas. 


\section{La Indumentaria y algunas Interpretaciones Estructurales}

Uno de los primeros estudios sistemáticos sobre indumentaria fue el efectuado por Kroeber y Richardson en 1940 sobre la evolución de estilos de los vestidos femeninos. Después de plantear que las modas y el estilo de la indumentaria reflejan las condiciones sociales y se mueven con el correr de los tiempos, concluyen diciendo:

... los aspectos fundamentales del estilo en contradicción a las fluctuaciones de la moda, estando esta definida en una época dada, son en gran medida inconscientes en cuanto a que se los considera axiomáticos (p. 135).

Si bien Kroeber y Richardson dejaron de lado las explicaciones psicológicas (pp. 136-137), Levi-Strauss en 1951 se encargó de inter pretar sus observaciones como evidencia de la operación de leyes subyacentes a fenómenos que podrían parecernos arbitrarios por observación superficial. Escribe sobre el particular:

Estas leyes no pueden deducirse de meras observaciones empíricas, o por consideraciones intuitivas al respecto, sino que resultan de medir varias relaciones básicas entre los diferentes elementos del vestido (p. 58).

El problema de analizar la indumentaria a este nivel reviste de carácter análogo al de los problemas de la lingüística estructural y de las ciencias naturales. La dificultad empírica radica en identificar los componentes básicos, los lineamientos y los sistemas de relaciones (o sistemas de comunicación) entre las unidades tomadas por separado y como agregados o agrupaciones. El problema no está simplemente en ver si la indumentaria puede estudiarse según métodos y conceptos similares a log de la lingüística, sino en ver como lo plantea Levi-Strauss, "estos no constituyen acaso fenómenos cuya naturaleza integral es idéntica a la del lenguaje" (p. 61).

El mejor ejemplo de abordar el estudio de la indumentaria según el modelo lingüístico está demostrado por la obra de Bogatyrev (1937) quien realizara esa labor mucho antes de que Levi-Strauss la considera- ra de utilidad. Si bien Bogatyrev no avanza hasta el punto de encontrar homologías estructurales entre el sistema del lenguaje y el sistema de la indumentaria, es suya la afirmación de que:

para llegar a captar la función social de los trajes hemos de aprender a interpretarlos como signos de manera parecida a como aprendemos a leer y escribir idiomas (p. 83).

Para Bogatyrev la "función de un vestido es la expresión de las actitudes propias de quienes lo emplean" (p. 93).

La función puede estar relacionada con el vestido mismo (como objeto) o con la variedad de aspectos de la vida, de que el vestido (como signı) es una indicación (p. 80, itálicas suyas).

De esta manera Bogatyrev nos anima a considerar además de las estructuras formales de la indumentaria, su proyección ética dentro de la sociedad. Pero para llegar a tal punto habremos de necesitar información y datos más allá de los aportados por la indumentaria en sí. Sus palabras:

Un vestido es como un microcosmos, donde se reflejan en su relativa intensidad los ideales estéticos, morales y racionalistas de quienes lo usan. Para poder apreciar a cabalidad el sitio de- la indumentaria como expresión de una ética autóctona, debemos reconocer los ideales éticos que refleja la forma del vestido (como por ejemplo las restricciones en cuanto a quienes pueden usarlo) y a su vez, debemos poseer conocimientos de los ideales éticos generales de aquel pueblo. De otra manera nos expondremos a pasar por alto la expresión de aquellos ideales que se reflejan en el vestido (p. 93, itálicas suyas).

Sería posible continuar por varias páginas extrayendo ideas de interés y datos de etnografía presentes en las obra de Bogatyrev y en el ensayo de introducción escrito por Ogibenin (1971, pp. 9-32), pero tal labor sobrepasa los límites de este artículo y por lo tanto, he de animar a quienes se interesan por el tema a consultar esta valiosa obra. 


\section{LA ESTRUCTURA SIMBOLICA DE LA INDUMENTARIA:}

\section{EL CASO DE LOS GUAMBIANOS}

Los Guambianos habitan una región de laderas en la margen occidental de la Cordillera Central, al suroeste colombiano. Antes de la llegada de los Españoles había más de cien (100) tribus en aquella región, pero la conquista, las enfermedades y el proceso colonizador han contribuído a eliminar muchas de ellas y a aculturar las que van quedando. No obstante los Guambianos, en contraste con lo anterior, han logrado mantener viva gran parte de su tradición cultural, incluyendo su idioma y una manera particular de vestirse.

El idioma Guambiano era considerado hasta hace poco como parte de la familia chibcha (Rivet, 1946), pero según estudio reciente sobre las lenguas Amerindias (Matteson, 1972, p. 22), a través de los siglos, palabras de origen quechua, páez y español, han sido incorporadas al Guambiano y hoy día la mayoría de sus gentes hablan también el español.

En el resguarho de Guambia vive un total aproximado de siete mil quinientos (7.500) indígenas, en una extensión calculada en seis mil (6.000) hectáreas y de la cual una mitad es terreno cultivable. La elevación del terreno varía desde dos mil seiscientos $(2.600)$ metros en la parte occidental hasta unos cuatro mil $(4.000)$ metros hacia el oriente. La región se puede dividir en tres (3) zonas ecológicas con características propias:

\section{El Páramo:}

Una zona fría, húmeda, cubierta de tierra apta para la agricultura. Esta zona es considerada "peligrosa" por estar habitada de numerosos espíritus relacionados con los fenómenos naturales; las mujeres, en particular, son susceptibles a aquellas influencias malévolas, pero todos los Guambianos cumplen un rito de "limpieza" antes de ascender hasta allí.

\section{La Zona Media:}

Consiste en su mayor parte de colinas onduladas y utilizadas generalmente para los cultivos de papa, ulluco y cebollas.

\section{La Zona Inferior:}

Al occidente, utilizada primordialmente para los cultivos de maíz, el trigo, la cebada y los fríjoles. La mayor extensión de sus tierras es demasiado accidentada para ser arada con animales de tiro $y$, por lo tanto, se cultiva con palas e implementos de madera rematados por puntas me tálicas.

En lo que va de este siglo la población guambiana ha aumentado desde unos mil quinientos (1.500) (en 1900) hasta unos siete mil quinientos (7.500) (en 1973); anteriormente había abundancia de tierras y bosques, pero hoy día toda la tierra está dividida en parcelas. A excepción de una, los Guambianos viven distribuídos por veredas, en las cuales residen desde veinticinco (25) hasta noventa (90) familias. La descendencia es bilateral y la residencia post-matrimonial es patri-virilocal. Durante el período que me sirvió de marco para obtener un modelo de su indumentaria, la década de 1920 y comienzos de 1930 , las veredas eran menos pobladas y los hombres obtenían sus esposas de otras localidades.

En general, las actividades agrícolas las efectúan conjuntamente el esposo y la esposa. Las mujeres, además de ayudar con los cultivos del campo, mantienen sus huertas, aunque la división del trabajo les asigna una función primordialmente hogareña: cocinar, criar los hijos y tejer las faldas $\mathrm{y}$ las ruanas. Los hombres emplean parte de su tiempo en actividades de tipo social (reparando caminos, construyendo puentes, etc.) así como también cuidando de los animales y fabricando sombreros. El trabajo recíproco entre familias y de manera cooperativa por el sistema de mingas es muy común.

La dirección política del resguardo está encomendada al cabildo indígena en el que todas las veredas tienen su representación. Solamente los hombres adultos son aptos para ejercer estas funciones y su período de servicio es por un año; los cargos más destacados casi siempre son ocupados por individuos que han tenido previa experiencia en posiciones inferiores. Servir en el cabildo significa sacrificar parte del tiempo y del dinero, pero no existen requisitos financieros para aspirantes a esa posición. Las funciones principales de los elegidos son las de dirimir posibles conflictos, supervisar la distribución de las tierras, organizar proyectos para la comunidad y patrocinar las celebraciones religiosas. Esta institución política no está favorecida, en ninguna forma por poderes sobrenaturales.

La perspectiva del Guambiano es una combinación de las influencias españolas, con sus creencias indígenas. La Iglesia Católica los bautiza, los 
une en matrimonio y los entierra, pero a estas dos últimas ceremonias le añaden ellos sus propias celebraciones. Reconocen la influencia de una gran variedad de espíritus sobrenaturales y con frecuencia recurren a sus ritos de limpieza para evitar contaminaciones que, según ellos, causarían enfermedades o la muerte; sobre todo las mujeres y los niños son susceptibles a los espíritus, así, por ejemplo, durante la menstruación, a la mujer se le prohibe realizar la mayoría de sus actividades normales.

Entre la cultura Guambiana predominan dos temas que operan a manera de principios orientadores de muchas de sus actividades. El uno es "la igualdad" (latá-latá) y el otro el del "acompañar" (linjab). El primero es el ideal de cómo deben ser las cosas, mientras el segundo realza el ideal de realizar actividades con otros y para otros e implica la existencia de la jerarquía y la reciprocidad.

\section{INDUMENTARIA GUAMBIANA Y LA ESTRUCTURA SOCIAL}

La indumentaria entre los Guambianos ha sido objeto de modificaciones a través del tiempo; y si bien los cambios drásticos han sido escasos, cada generación se ha encargado de añadirle sus propios retoques, de tal manera que resulta imposible señalar una cierta moda como característica de toda la sociedad en una época determinada. Así, por ejemplo, durante mi primera visita al resguardo en el año 1962 se podía observar todavía entre los hombres de más edad el uso de la pantaloneta blanca que fuera típica del vestido en los siglos dieciocho y diecinueve. Existe, no obstante, la tendencia entre la mayoría de la gente a adoptar el uso de una prenda nueva, una vez haya sido introducida.

Hacia fines del siglo pasado y comienzos del presente se produjo un cambio drástico en indumentaria: los hombres comenzaron a fabricar los sombreros redondos y aplanados que toman una forma cónica sobre la cabeza y fueron adoptados como prenda insustituible de la indumentaria tanto masculina como femenina. También se inició por esta época (década de 1920) la costumbre entre los hombres de llevar una faldilla azul puesta sobre la pantaloneta blanca y confeccionada del mismo material azul con que las mujeres hacen sus chales.

El modelo de indumentaria presentado en estas páginas fue típico del resguardo desde 1920 hasta comienzos de 1930, siendo varias las razones que nos indujeron a seleccionar la moda de esta época como tema
MUJER
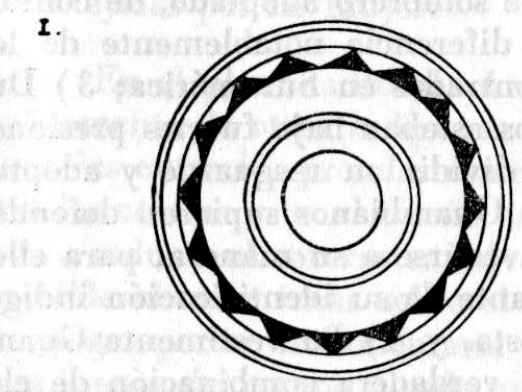

II
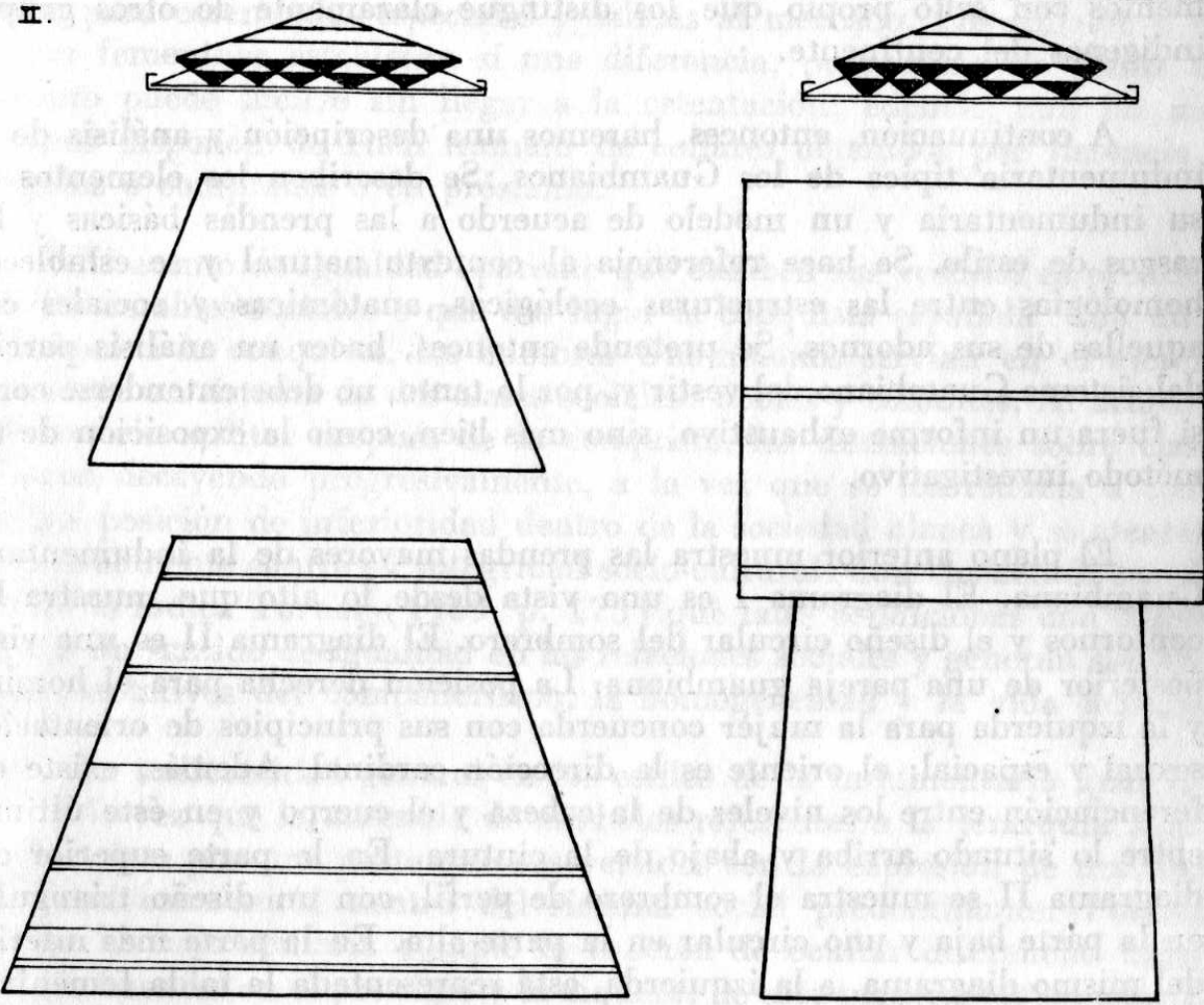

\begin{tabular}{|c|c|c|c|c|}
\hline FABRICANTE & PRENDA & RASGOS & IZ OUIERDA - MUJER & DERECHA - HOMBRE \\
\hline \multirow{2}{*}{ HOMBRE } & \multirow{2}{*}{ Sombrero } & Forma & Cónica & Cónica \\
\hline & & Disoño & Clrculos - Trióngulos & Círculos - Trióngulos \\
\hline \multirow{3}{*}{-MUJER } & \multirow{3}{*}{ vano } & Diseño & Lineas horizontoles & Lineos horizontales \\
\hline & & Node lineos & Impares $(7,9,11)$ & Pares $\left(2,{ }^{\circ}\right.$ grupos de 2$)$ \\
\hline & & Linoomiento & Simétrico & Asimétrico \\
\hline
\end{tabular}


del estudio. 1) El uso de la faldilla azul entre los hombres representa un cambio efectivo hacia una prenda que, según relatan algunos, era usada antes de la conquista; 2 ) El tipo de sombrero adoptado, de contornos redondeados y apariencia cónica, se diferencia notablemente de los demás tipos de sombreros indígenas encontrados en Suramérica; 3 ) Durante este mismo período los Guambianos estaban bajo fuertes presiones de la gente blanca de la localidad para dividir su resguardo y adoptar maneras occidentales de vestirse, pero los Guambianos supierori defender con tenacidad sus tierras y el derecho a vestirse a su manera; para ellos su indumentaria era un símbolo importante de su identificación indígena, la cual deseaban mantener a toda costa, y 4) La vestimenta Guambiana examinada en conjunto revela una verdadera combinación de elementos con sello propio que los distingue claramente de otros grupos indigenas del continente.

A continuación, entonces, haremos una descripción y análisis de la indumentaria típica de los Guambianos. Se describen los elementos de su indumentaria y un modelo de acuerdo a las prendas básicas y los rasgos de estilo. Se hace referencia al contexto natural y se establecen homologías entre las estructuras ecológicas, anatómicas y sociales con aquellas de sus adornos. Se pretende entonces, hacer un análisis parcial del sistema Guambiano del vestir y, por lo tanto, no debe entenderse como si fuera un informe exhaustivo, sino más bien, como la exposición de un método investigativo.

El plano anterior muestra las prendas mayores de la indumentaria Guambiana. El diagrama I es una vista desde lo alto que muestra los contornos y el diseño circular del sombrero. El diagrama II es una vista posterior de una pareja guambiana. La posición derecha para el hombre y la izquierda para la mujer concuerda con sus principios de orientación sexual y espacial: el oriente es la dirección cardinal. Además, existe diferenciación entre los niveles de la cabeza y el cuerpo y en éste último, entre lo situado arriba y abajo de la cintura. En la parte superior del diagrama II se muestra el sombrero de perfil, con un diseño triangular en la parte baja y uno circular en la parte alta. En la parte más inferior del mismo diagrama, a la izquierda, está representada la falda femenina; el diseño consiste en un número impar de líneas horizontales arregladas simétricamente de arriba hacia abajo, sobre la falda está la manta azul hecha de material obtenido en el comercio. A la derecha de la manta está el bosquejo de la ruana masculina; el diseño consiste en dos bandas horizontales o grupos de bandas, colocadas asimétricamente en la mitad inferior de la prenda; debajo de la ruana está la faldilla hecha del mismo material azul de las mantas femeninas. Los sombreros son hechos por los hombres y carecen de rasgos de construcción o de diseño que indiquuen diferenciación sexual. Todas aquellas prendas usadas por debajo del euello son tejidas por las mujeres.

En el plano cultural, el vestido de los Guambianos los distingue visiblemente de otros indígenas en el mundo de los blancos. Existen diferencias entre las prendas masculinas y las femeninas, pero la semejanza en los colores y en el diseño así como la igualdad en los sombreros, tiende a reducir el contraste. Salvo en casos de extrema pobreza, resulta imposible obtener ideas sobre el status socio-económico de un Guambiano, a juzgar por su indumentaria porque emplean los trajes más viejos para las faenas del campo y cada uno dispone de por lo menos un conjunto de ropa para ceremonias especiales y salidas al mercado. Los collares y las joyas femeninas establecen sí una diferencia, pero existe un límite en cuanto puede lucirse sin llegar a la ostentación; además, aun las más pobres disponen de buen número de collares obtenidos por herencia y regalos o comprados o en préstamo.

El acento de igualdad aparente que exhiben sus vestidos es producto de los cambios sociales a que dio lugar la conquista española. Con anterioridad a la conquista, los hombres Guambianos servían en el ejército y existía un sistema de dos clases sociales: nobles y comunes. Al acabarse el servicio militar después de la conquista, las distinciones sobre clases fueron decayendo progresivamente, a la vez que se los reducía a todos a una posición de inferioridad dentro de la sociedad blanca y se atentaba continuamente contra su integridad socio-cultural. Con frecuencia sucede, como lo indica Turner $(1969$, p. 175$)$ que tales condiciones dan ímpetu hacia un sentido de igualdad en las relaciones sociales y generan símbolos representativos del compañerismo, la homogeneidad y la vida comunal.

La uniformidad general en los estilos de la indumentaria guambiana, a la vez que la ausencia de símbolos referentes a la jerarquía social, nos sugiere por una parte que sus vestidos son la expresión de una inferioridad estructural dentro del sistema social predominante. Por otra parte, su indumentaria cumple la función de ocultar diferencias individuales basadas en el prestigio y la riqueza, de esta manera "toma cuerpo" el principio de igualdad.

El plano y los diagramas presentados atrás nos indican los dualismos presentes de varias maneras en la indumentaria guambiana. Las mujeres confeccionan las prendas del torso para sí mismas y para los hombres, estos, a su vez, producen los sombreros que llevan puestos ambos sexos. 
Una de las dificultades para la interpretación de las prendas y su ordenamiento general, es que los Guambianos no le confieren valor simbólico a las prendas o a muchos aspectos de su indumentaria, salvo como medio de su identificación sexual y cultural. Si bien los colores poseen importancia simbólica en los vestidos de gala, los colores en las prendas cotidianas son idénticos, excepto tal vez del verde que se observa ocasionalmente en la ruana del hombre ( ¿hombre = hoja de coca?). De esta manera, los valores y significados que puedan tener han de ser derivados del contexto mismo.

Se observan dos orientaciones en las prendas mayores de los Guambianos: una latitudinal dividida en izquierdo y derecho según la dicotomía femenina vs. masculino, y otra altitudinal dividida en dos regiones: superior e inferior, cabeza y torso. La región inferior, o torso, puede ser subdividida, a su vez, en dos partes, según sea por debajo o por encima de la cintura. Si bien es cierto que la falda y la ruana presentan colores semejantes y el mismo diseño de líneas horizontales, existen diferencias en el número de líneas empleadas (impar vs. par), en su respectivo ordenamiento (simétrico vs. asimétrico) y en la posición en el cuerpo (abajo/arriba). Los términos que se utilizan en guambiano para estas prendas indican que el contraste "abajo vs. arriba" posee su significado, pues el morfema lend es "abajo" o "inferior" y la palabra que denota la falda femenina es lendik. En contraste, tur significa "arriba" y "cabeza", y turí es el vocablo que denota a la ruana masculina. En consecuencia, aun antes de tocar lo referente a la simbología del sombrero resulta evidente la asociación de la mujer con la izquierda y lo de abajo, y del hombre con la derecha y lo de arriba.

En el plano superior, el de la cabeza, están los sombreros hechos por los hombres que, como ya se mencionó, son idénticos para ambos sexos. La parte alta del sombrero siempre lleva círculos, mientras la baja contiene triángulos. Entonces, a nivel de cabezas y sombreros, la izquierda y la derecha son iguales y desde el punto de vista de lo estético, los sombreros contribuyen con una sensación de simetría y unidad dentro del conjunto de sus vestidos.

Volviendo al tema de las relaciones sociales, se pueden dividir las actividades primarias en dos: 1) donde priman las funciones corporales, tales como la producción, y 2) donde priman las funciones del orden alrededor de: a) lo social (la política), y b) lo sobrenatural (la religión). Encontramos entonces que los principios orientadores de este tipo de actividades son homólogas a los que exhiben la indumentaria de los Guam- bianos. Para comenzar hay que notar que las actividades productivas y reproductivas tienen que ver fundamentalmente con las regiones inferior y media del cuerpo, las mismas se llevan a cabo en las zonas baja e intermedia del resguardo, de tal manera que unifica el trabajo de hombres y mujeres en unas actividades y los divide en otras.

Tanto los hombres como las mujeres trabajan juntos en los campos, se unen para fines sexuales, pero se dividen para cazar (actividad masculina), y para cocinar, tejer y dar a luz (actividades femeninas). La desigualdad presente en este nivel "inferior" revela la mayor importancia del lado femenino y de la región más baja del resguardo; son las mujeres quienes confeccionan las prendas del torso y se las pasan a los hombres. Este ordenamiento asimétrico de lo corporal está balanceado a su vez por la estructura de lo tocante a la preservación del orden y el ejercicio de la autoridad dentro de la comunidad.

Los hombres hacen los sombreros y los dan a las mujeres. Simbólicamente ellos unen a la pareja al ignorar diferencias entre la izquierda y derecha, femenino y masculino. El contraste sombrero vs. trajes revela una estructura simbólica y análoga a la del cuerpo humano, es abajo del cuello y no arriba, en donde se presentan diferencias anatómicas notables. Los hombres trabajan los sombreros y a un nivel institucional, son ellos quienes ocupan los puestos políticos en el cabildo. La función de esta organización es mantener la unidad entre veredas distanciadas y entre otras cosas, construir los puentes que las acercan. Además, la política es un asunto "capital", asunto de hombres; los hombres de poder en Guambia son aquellos que "entienden" y hablan con persuasión y la localización del poder político tiende a situarse hacia la parte más alta, la región oriental del resguardo. De allí han salido más del $90 \%$ de.los gobernadores que ha tenido el resguardo en lo que va de este siglo. Como resultado, la dinámica de los sombreros, yendo de derecha a izquierda, contribuyen a la unidad estética de la indumentaria y a su vez a la dinámica del poder político de derecha a izquierda, de superior a inferior, de oriente a occidente y sirve para preservar la unidad política del resguardo.

Un área más de las relaciones sociales donde se mantiene la influencia masculina y simbólicamente también el sombrero, es en la religión. Aquí cabe hablar sobre las estructuras de la autoridad entre los seres humanos y los espíritus. Dentro del marco espacial y social de los Guambianos ambas estructuras coexisten en relación inversa: el control humano es más efectivo hacia los niveles bajos y va disminuyendo a medida que se asciende hacia las regiones altas del resguardo y aun más allá. En las partes altas se utilizan fetiches para proteger los cultivos 
y en el páramo habitan animales salvajes y poderes sobrenaturales de peligro para el hombre y aun más para la mujer, que puede resultar embarazada por espíritus que habitan allí. Toda acción religiosa tendiente a mediar entre la sociedad humana y la sobrenatural es prerrogativa de los hombres y, por consiguiente, el sombrero no solo simboliza el status político de los hombres, sino también su posición de curanderos, adivinos y brujos.

En breve, las prendas de la indumentaria Guambiana en relación con las partes del cuerpo humano, reflejan una simbología de características semejantes a la que orienta sus actividades y estructuras sociales. El resultado podría ser tomado como una transformación de los principios Guambianos de la lógica social al plano de la indumentaria.

Las dimensiones estéticas y éticas serían una ordenación de unidades binarias estructuradas a lo largo de ejes opuestos, pero complementarios uno de otro. Las mujeres producen las prendas que cubren la parte inferior del cuerpo, las cuales exhiben unidad y oposición de izquierda y derecha, a la vez que la jerarquía de lo masculino sobre lo femenino (la ruana sobre la falda). De manera similar, las actividades sociales en lo que respecta a la producción establecen una mayor funcionalidad para las mujeres, pero la autoridad la ejercen los hombres. Estos, a su vez, fabrican los sombreros iguales para el hombre y la mujer y su autoridad predomina en todos los aspectos de la vida, sirviendo de políticos y chamanes para mantener el orden político y religioso. En sentido retórico el sombrero viene a simbolizar la unidad, la igualdad y la simetría de la sociedad vinculando a los hombres; refleja, por otra parte, la jerarquia explícita de la cabeza sobre el resto del cuerpo; del cielo, la lluvia y los espíritus sobre la tierra y del hombre sobre la mujer. . . por lo menos es lo que parece.

Todavía nos quedan por examinar varios detalles de la indumentaria Guambiana y su relación con el contexto social. Tenemos, por ejemplo, los detalles internos del diseño, según los cuales se nota que la falda femenina presenta un número idéntico de líneas horizontales, arregladas simétricamente a lado y lado de la mitad inferior de la prenda. En lo que respecta a las figuras deçorativas tejidas en los sombreros se nota la colocación de los círculos arriba y de los triángulos abajo, figuras geométricas éstas que son símbolos de importancia en otros sectores que tienden a asociar a las mujeres con los círculos y a los hombres con los triángulos.

De esta forma se nota cómó el mensaje que comunican los aspectos decorativos de su indumentaria parece ser el opuesto del que se expresa mediante la colocación de sus prendas. En el caso del diseño la mujer está simbólicamente asociada a la simetría y el hombre a la asimetría; así mismo, las mujeres (círculos) están superpuestas a los hombres (triángulos).

Cabría preguntarnos entonces si estos símbolos tienen vinculación alguna con la cultura y la estructura social de Guambia. La respuesta es afirmativa sólo para el plano de lo que Levi-Strauss (1953) llama "estructuras inconscientes" y que yo prefiero llamar "estructuras que no se comentan a menudo". A este nivel los hombres están vinculados con una división estructural en el tiempo y el espacio, mientras las mujeres lo están con su respectiva unidad. Tenemos así que en Guambia las veredas están compuestas de parientes masculinos vinculados patrilíneamente, a lo que han contribuído regulaciones sobre residencia patri-virilocal y exogamia femenina; pero estos grupos van unidos estructuralmente mediante la comunicación entre sus mujeres. En cuanto al papel de la mujer para conservar la unidad a través del tiempo, lo mismo que su posición superior a los hombres, la explicación se nos presenta en términos bastante claros: Mamá Manuela Caramaya es la mamá legendaria de los dos hombres, Tumiñá y Tombé, de quienes descienden los Guambianos hispánicos actuales (Hernández de Alba y Tumiñá P., 1949), iy las mujeres son quienes tienen a los hijos!

Las observaciones anteriores sobre la indumentaria y la estructura social de la población Guambiana nos ayudan a percibir más claramente el papel simbólico de los trajes en la dialéctica de la vida social.

Aunque sean algo común y corriente, los vestidos forman parte esencialísima de la comunicación social al ayudarnos a definir las situaciones mediante la acentuación directa de ciertos principios y el ocultamiento inconsciente y la ambigüedad de ciertos otros.

Si bien la indumentaria varía en su forma simbólica de expresar el cómo, el qué y el cuándo del comportamiento, siempre ha de constituír (aunque esté ausente) una parte integral del proceso y de la estructura de la acción. Así como se puede tejer textura sobre un pedazo de tela para ocultar los hilos de la urdimbre, así mismo una sociedad puede tejer una textura social que, por una parte, exhiba públicamente una serie de normas, mientras que por la otra oculta otra serie por conocer.

Análogamente, símbolos de unidad y jerarquía (que casi siempre van juntos) expresados a través de roles y status, pueden convertirse sin 
querer en soportes del mismo sistema que están tratando de ocultar. En las tierras de Guambia la función retórica del sombrero es la de comunicar un mensaje de unidad y jerarquía y de asociar éstas con el hombre. Sin embargo, al examinar sus elementos decorativos encontramos alli los principios básicos que trata de ocultarnos el sombrero: círculos sobre triángulos, es decir, las mujeres sobre los hombres.

\section{LA NATURALEZA, LA CULTURA Y LA INDUMENTARIA}

En un libro reciente Murphy (1971, p. 71) hace la siguiente observación sobre el estado actual de la teoría antropológica:

No sólo hemos dejado de volver a las preguntas fundamentales... sino que hemos olvidedo cuáles eran.

Espero entonces que el razonamiento sobre cómo y por qué se viste el hombre, así como también lo que sucede una vez vestido, sea un paso hacia lo fundamental. Puesto que alguna forma de indumentaria es un componente universal de los grupos humanos, resulta apropiado pregun tarse sobre su función para la sociedad en general y para una determinada sociedad en particular. Una respuesta inmediata y que además deja de lado la controversia sobre lo modesto y lo inmodesto, es aquella en que la indumentaria tiene algo que ver con la imagen que el hombre tiene de sí mismo frente al mundo que percibe. En sus vestidos y adornos ve mos al hombre utilizar la naturaleza (el componente material) para rechazarlo o distinguirse de ella (animales y la desnudez humana) y dar realce al aspecto esencialmente humano o cultural de la vida. Al referirse a las apariencias corporales así como a los vestidos, Ogibenin (1971, p. 14) sugiere que ambos factores merecen consideración:

Puesto que al ser utilizados como signos en las sociedades humanas constituyen una zona fronteriza e ilustrativa de fenómenos de transición entre la naturaleza y la cultura. En esta área y con referencia a una cultura específica, tal vez se podrían buscar analogías ontogenéticas sobre el comportamiento pre-cultural del hombre, pues aquí los estímulos psico-biológicos y psico-sociales originan reaccio- nes diferentes, de las cuales resultan conjuntos "objeto-signo" que corresponden a niveles de intersección del hombre con la naturaleza.

Continúa diciendo el investigador que si bien es cierto que las funciones del vestido son proteger contra el frío y el calor y cubrir la desnudez, "aparece primordialmente como el resultado de la habilidad humana en contrarrestar las fuerzas de la naturaleza" (p. 15). Un ejemplo del uso del adorno para efectuar esta transición puede verse en los rostros pintados de los Caduveos. Levi-Strauss (1963, p. 176) escribe al respecto:

Para los Caduveos, la pintura del rostro confiere al individuo su dignidad como ser humano; le ayuda a cruzar la frontera entre la naturaleza y la cultura y entre el animal "irracional" y el hombre civilizado.

Algo semejante aparece en el mito sobre la creación de una tribu Amazónica: después de colocar a los hombres en la tierra, el sol repartió entre los grupos implementos, armas, una canasta, una máscara y guayucos, aunque a los Desana solo les dio una cuerda (Reichel-Dolmatoff, 1971 , p. 27). El tratamiento así acordado al vestido, como un elemento simbólico de la separación del hombre de la Naturaleza, cubre la primera de las dos grandes áreas que mencioné anteriormente: la indumentaria respecto al Hombre tomado natural y culturalmente. Resta todavía plantear la relación del vestido entre los hombres mismos o más concretamente, de la indumentaria con respecto al hombre y a la mujer.

\section{LA INDUMENTARIA Y LA DOMESTICACION DE LA MUJER}

La década actual es quizá la menos indicada para entrar en un debate hipotético sobre la desigualdad de los sexos, pero el tema resulta inevitable dadas las características del presente estudio. Los planteamientos resultan difíciles debido no solo a la definición ambigua de la igualdad entre los sexos predominante hoy día, sino al gran número de hipótesis y evidencias presentadas, cada una de las cuales contiene granos de 
verdad. Después de leer exhaustivamente lo que se ha escrito sobre el hombre primitivo y sus vestidos y tras un esfuerzo de cinco años por tratar de entender la indumentaria peculiar de la tribu en que vivi, he intentado en varias oportunidades enfocar el tema desde el ángulo propio de estas gentes. No me estoy refiriendo aquí a los filósofos primitivos, aquellos que lanzaron a Levi-Strauss a trabajar por muchos años, sino más bien al individuo común y corriente, a aquel que si bien no está dado a las formulaciones mitológicas, sí tiene que afrontar los problemas existentes presentes en el mito.

En reciente entrevista (Hess, 1972) Levi-Strauss nos recuerda que "el primer problema del pensamiento místico es que las mujeres deben ser domesticadas". Yo me permitiría añadir que la indumentaria fue parte esencial de este proceso y en el orden de las realidades diarias fue quizás más importante que el mito. Para presentar tal aseveración me fundamento en la interpretación personal de hechos que paso, a continuación, a resaltar. Estos tienen que ver con lo que han sido y todavía son en muchas partes del mundo, las ideas del hombre primitivo sobre la mujer y también con hechos sobre el hombre mismo.

\section{La madre Naturaleza y sus hijas}

A la mujer se la considera por lo general "más próxima" a la naturaleza que el hombre y su relación con la naturaleza "más íntima" y directa que la del hombre. Las mujeres pueden ser fertilizadas por influencias poderosas de la Naturaleza, a menos que sean protegidas o prevenidas con anticipación. Si eso sucediera ¿cómo quedarían los hombres?

\section{La Mujer es Poderosa y Necesaria}

Las tallas más primitivas del cuerpo humano son las figurillas femeninas de características sexuales pronunciadas que han sido halladas en las tumbas Auriñaciences. Estas han sido tomadas como muestras simbólicas de la fertilidad primitiva y evidencia de la preocupación del hombre y su respeto por el poder procreativo de la mujer.

\section{La Mujer es un "peligro"}

El poder de las mujeres para causar enfermedades y otras desgracias entre ellas, a su familia, o a su comunidad, es una creencia genera- lizada entre pueblos primitivos. Las mujeres son "un peligro", sobre todo durante la menstruación y después del alumbramiento, y han de adoptarse medidas especiales para protegerlas de los poderes malévolos tanto por su propio bien como por el de los demás.

\section{La Mujer es "ambigua"}

Este no es un punto de vista separado, sino que más bien se refiere al conjunto de sentimientos expresados en las tres aseveraciones anteriores. El resultado psicológico es el de ambivalencia.

\section{La Mujer está a la izquierda, el Hombre a la derecha}

En todos los dualismos culturales basados en la dirección izquierdaderecha, a la mujer se la relaciona con la izquierda. Entre las cualidades asociadas comúnmente con este factor se cuentan: la impureza, la muerte, la humanidad, la enfermedad, la desnudez y la disolución. Asi mismo, las cualidades opuestas se le atribuyen al lado derecho.

\section{La Sexualidad de la mujer está más "dispersa"}

Este punto de vista ha sido presentado por Flugel (1950) y apoyado por los psicoanalistas (Hirning, 1961, p. 270) quienes afirman que la totalidad del cuerpo femenino está sexualizado "mientras que en el hombre la libido está más precisamente localizada en el área de los genitales". Las mujeres poseen actitudes más "sanas" o "naturales" en cuanto a la desnudez, lo que les permite disfrutar más holgadamente el placer de descubrirse, sin necesidad de llegar hasta el acto sexual (Flugel, 1950, p. 109).

\section{Los hombres primitivos "se visten de gala"}

En las sociedades primitivas, como entre los mamíferos y los pájaros, los machos se adornan más que las hembras. Si bien existe una serie de motivos para tal costumbre, el consenso general de la "domesticación de la mujer". Por domesticación me refiero fundamentalmente a dos actividades: el obtener el control y el conservarlo no a través del uso de la fuerza sino creando una situación de orden físico y cultural en la que los valores compartidos mantengan a los participantes juntos. 
El uso de prendas para vestirse y adornarse parece estar funda: mentado psicológicamente en el deseo del hombre de acompañarse de la mujer sexual y socialmente y de su poder misterioso para procrear y menstruar periódicamente. Si tenemos en cuenta sus actitudes ambivalentes hacia la mujer y el deseo de controlarla, el uso retórico, de diversas prendas, por parte de los hombres, para atraerla sería una modalidad lógica y efectiva. Resulta halagador pensar que alguien "se viste de gala" para ganarse nuestra atención, pero al mismo tiempo éste es el primer paso en el camino hacia las relaciones sexuales, el matrimonio y la familia. Una vez establecido el uso de una prenda o adorno dentro de un grupo es claro que puede ser utilizado culturalmente en otras situaciones, entre las cuales una de las más importantes es la de protegerse de los seres supernaturales.

Entonces lo que se plantea aqui es que si bien es cierto que el uso inicial de prendas de vestir y adornos por parte de los hombres se deriva de su deseo primario de atraer a la mujer, el uso del mismo por parte de la mujer tiene el objeto de "separarla" de la Naturaleza y "protegerla" de las fuerzas malévolas sobrenaturales. Puesto que generalmente son los hombres y no las mujeres los que se entienden con lo exterior, bien sea como cazadores o como chamanes, la manera de adornarse las mujeres podría simbolizar su aceptación a un mundo en que los hombres intervienen como mediadores y manipuladores de las fuerzas misteriosas que acarrean beneficios o desgracias para la comunidad humana.

En esta forma la indumentaria, nexo del hombre con lo divino, se convirtió en el mecanismo retórico para dirigirse y atraer el sexo opuesto. Más tarde fue utilizado como protección contra fuerzas capaces de producir enfermedades o embarazos y en esta forma empezó a asociarse con la idea de la inferioridad de la mujer dentro del marco cultural manejado por los hombres. Tal vez sea injusto, pero tenemos que recor dar que fue Eva quien probó primero la manzana.

\section{EL ANTROPOLOGO Y LOS HOMBRES IMPORTANTES}

Empezamos este trabajo con la aseveración de que los antropólogoś sociales le habían dedicado escasa atención al papel que desempeña la in. dumentaria. Parece apropiado entonces concluír preguntándonos por qué ha sucedido ésto; si nos hemos ocupado de la clitorectomía y de la ambigüedad, de la hechicería y de lo profano, de lo patrilíneo y de lo patrilocal, ¿por qué no nos hemos ocupado del vestido? A veces se menciona cuando resalta como atuendo de ceremonias, o como privilegios del jefe; pero normalmente la extraña vestimenta de los nativos se desvanece en nuestra memoria, solo para ser resucitada con ocasión de un coctel, cuando atraemos la atención de los demás al ataviarnos con prendas adquiridas en la escena de nuestras investigaciones. Con frecuencia, nuestros hogares están también adornados con extraños artefactos como em. blema de nuestra localización ambigua dentro de la sociedad y de la comunidad intelectual. El contraste entre la forma como relacionamos la cultura material de las sociedades que investigamos con nuestros escritos y nuestra vida privada me sugiere una paradoja dentro de la vida del antropólogo. Por todo lo material que exhibimos nos distinguimos de la sociedad a la que pertenecemos, pero al prestar mínima atención a las prendas que coleccionamos estamos revelando accidentalmente que después de todo pertenecemos a la Subcultura de los Hombres Importantes. Entre ellos "el tema de la indumentaria es un tabú. Ni siquiera desean dar a entender que se preocupan al respecto... sobre el sexo, está bien, hablamos cuanto queramos, pero sobre la indumentaria ni una palabra". (Tom Wolfe, 1966, pp. 231-2). 
MOSQUERA, Tomás Cipriano de

\section{NOT A}

Este artículo fue escrito originalmente en inglés y la traducción fue hecha por el señor Fabio Ocaziones. La versión en inglés será publicada en: The Fabric of Cultures: Essays in the Anthropology of Clothing and Adornment. J. Cordwell and R. A. Schwarz, editors. The Hague:
Mouton.
1855

MURPHY, Robert F.

1964

1971

NADEL, S. F.

1954

NEEDHAM, R.

1960

OGIBENIN, Boris L.

1971

OTTEN, Charlotte M., Editor.

1971

Memoria sobre la geografía física y política de la Nueva Granada. New York.

"Social distance and veil". En: American Anthropologist. 66:1257-74.

The dialectics of social life, Bașic Books N. Y.

Nupe religion. Routledge \& Kegan Paul, London.

"The left hand of the Mugwe: an analytical note on the structure of Meru symbolism". En: Africa 30 ,

"Peter Bogatyrev and structural ethnography" in The functions of folk costume in Moravian Slovakia bi petr Bogatyrev, Pp. 9-32 Mouton \& Co. N. V. The Hague.

Anthropology and art. American Museum Sourcebooks in Anthropology, Q 13. The Natural History Press. Garden city, New York.

PARSONS, Elsie Clews.

1936

Mitla: town of the souls. University of Chicago Press. Chicago.

REDFIELD, Robert.

1930

Tepoztlán. The University of Chicago Press. Chicago.

REIQHEL-DOLMATOFF, Gerardo and Alicia

1961

The people of Aritama. Routledge \& Kegan Paul. London.

RICHARDSON, J. and A. L. KROEBER.

1940

"Three centuries of women's dress fashions" in Anthropological Records Vol. 5 .

RIVET, Paul

1946
"Le groupe Kokonuko" En: Journal de la Societé des Américanistes, 33:1-61. 
ROACH, Mary Ellen and BUBOLZ EICHER, Joanne, Editors.

1965

Dress adornment, and the social order, John Wiley \& Sons, Inc. New York.

SANBORN, Herbert C.

1926

"The function of clothing and of bodily adornment". The American Journal of Psychology 38:1-20.

SIMMEL, Georg.

1950

SPENCER, B. and F. J. Guillen.

The sociology of Georg Simmel Translated by K.H. Wolff. The free Press. Glencoe, Illinois.

1899

The native tribes of Central Australia,

STURTEVANT, William C.

1967

"Seminole men's clothing" in: Essays on the verbal and visual arts. Edited by June Helm, pp. 160-174. University of Washington Press. Seattle.

THOMAS, W.I.

1909

Source book for social origins. R. G. Badger. Boston.

TURNER, Victor

1967

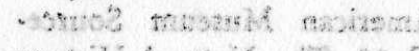

The forest of symbols. Cornell University Press. Ithaca.

1969

The ritual process: structure and anti-structure. Aldine. Chicago.

VOGT, Evon Z.

1969

Zinacantán. The Belknap Press of Harvard University Press. Cambridge, Massachusetts.

WWESTERMARCK, E.

1921

A history of humah marriage. London.

WILSON, M. 1957

Ritual of kinship among the Nyakyusa. Oxford University Press, for the International African Institute. London.

WOLFE, Tom. 1966

"The secret vice" in: The Kandy-kolored tangerineflake streamline baby. pp. 229-35. Cardinal pocket book. New York. 